\title{
THE SUPPORT OF MATHEMATICAL RESEARCH BY THE NATIONAL SCIENCE FOUNDATION
}

\author{
WILLIAM L. DUREN, JR.
}

1. The present terms of support of mathematics by the Foundation. The writer has recently completed a short term as Acting Program Director for Mathematics in the National Science Foundation. One residue of this experience is the realization that the National Science Foundation Act of 1950 did not in itself create a new era in which a non-military arm of the Government will support basic research in theoretical mathematics without the demand of direct military or even physical science relatedness. It will take a great deal of building within the framework of the Act to realize this objective. The mathematicians, who are without doubt the poorest politicians in the world, do not seem to realize that a non-military arm of the Government must show the actual need and must justify the requests for appropriations for mathematics in itself instead of asking for appropriations for the defense of the country, a much stronger appeal. Hence we must express our needs for support from the National Science Foundation in the form of proposals. These can be submitted to more than one agency if both agencies are so informed.

The submission of these proposals should be regarded as a form of public service or service to mathematics. Inevitably some good proposals will have to be rejected until adequate appropriations are secured to permit the support of mathematics in ways not now covered by the military agencies. We must accept this outcome without wounded feelings, for the principles which govern the decisions on what to support and what not to support, or even what can be supported, are not formulated. Moreover one cannot expect a full explanation of the reasons for rejection of any particular proposal while another is granted. This is too difficult.

To date, the National Science Foundation has granted a number of predoctoral and postdoctoral fellowships in mathematics, has made a few individual research grants and one group research grant, has provided for the support of a Summer Research Institute in mathematics, has set up a provision for assisting in travel to foreign scientific meetings which has benefitted some mathematicians and has made an arrangement with the National Bureau of Standards for making high-speed digital computation available for non-military research in universities. It is supporting a survey, jointly with other agencies, of Applied Mathematics. It is also considering the support 
of mathematics publication, a research conference in mathematics, and a Summer Institute for college teachers of mathematics.

2. The individual project. To submit a proposal for individual research, which is ordinarily granted only to scientists of proved ability in research, one should describe the proposed research in such a way that it can be understood by reviewers who are expert in the field of the investigation. The proposal must be submitted through the proper administrative channels in the institution. The budget ordinarily calls for the payment of the academic salary of the principal investigator and his junior associates, who may be either predoctoral or postdoctoral research men. This mechanism provides for the support of young postdoctoral research men when they can be associated with some senior investigator who applies for the grant. The senior investigator need not participate in the budget himself; in fact he usually does not do so in experimental science grants. An Assistant Professor who wishes to apply for full time research at some large center would do well to apply from his own university if he comes from a smaller school, rather than from the place where he wants to work. These forms of individual research grants can be used to achieve somewhat the same objectives as postdoctoral fellowships, which are now few in number. Fiscal details are described in a "Guide for the Submission of Research Proposals" obtainable from the National Science Foundation, Mathematical, Physical and Engineering Sciences Division, Washington 25, D.C.

3. A plan for a continuing group research project. Next, I should like to describe a kind of continuing group project which can be used to support a department active in graduate work and research without asking for a "block grant," which would almost certainly be rejected. This group project is designed primarily to support a secondary center which does not already have substantial Government support in the form of fellows, individual grants or special contracts. It may be expected that, to be approved, such a proposal for a group research contract must come from a department which can show evidence of initiative from within and achievements in research prior to submitting the proposal; especially it must have students and a proper environment with some assurance of stability and of support by its own university. The proposal should describe the contributions of the university in the form of tenure appointments to men of professorial rank (still a contribution little appreciated by government administrators whose grants and contracts cannot provide tenure), graduate teaching, libraries, secretarial staff, office space, etc. 
A mathematical subject of the proposal for a group research grant is chosen so as to be fundamental enough to lie in the core of graduate training of any mathematician and broad enough to cover the researches of a small group of mature mathematicians with their junior research associates. Normally, these are recent Ph.D.s or men who have passed the preliminary examination for the doctorate, but don't call them fellows or students! The work is characterized by research seminars rather than by the traditionally solitary studies of the mathematician. Formal courses are, of course, outside the project. The proposal will describe the general methods of study so that the project can be reviewed for scientific merit in the same way as an individual proposal. Once approved, the continuation of the grant cannot legally be guaranteed and will undoubtedly depend upon the achievements of the group. Thus the judgment of the consultants remains as an assurance of the quality of the performance.

It is not unrealistic to conceive that there might be ten to twenty such group research projects in the United States, supported by the Foundation or ONR, or perhaps other military agencies, in departments which are doing basic graduate training, each having an annual budget of the order of $\$ 30,000$. (For a large department a budget of $\$ 5,000$ is more in keeping with present limitations.) This might include $\$ 12,000$ for summer research, $\$ 12,000$ for research associates during the regular year and $\$ 6,000$ for travel, preparation of manuscripts, consultants' expenses for short-term visitors who may lecture as well as "consult," publication costs by all means, and "indirect costs" not exceeding 15 per cent of the total. The publication item might cover estimated page costs of publication done under the project.

4. Other possibilities. The National Science Foundation has a clear charge to support basic research and it may work by grants instead of contracts. This liberalization of principle in comparison with military agencies could be explored to determine if there are not other good ways to promote the welfare of mathematical research and training, and the service of mathematics to the sciences with or without grants of funds. Some things which are now difficult, if not impossible, are: support of the writing of books to be published commercially, non-scientific equipment or books for universities, extra jobs of research which will increase the rate of pay of the scientist, foreign travel except to foreign scientific meetings, sabbaticals (in the free sense), and any project calling for support in perpetuo.

These suggestions are by no means an official statement from the National Science Foundation and may disagree with its policies. The 
other agencies, the Office of Naval Research, the Office of Ordnance Research, and the Office of Scientific Research of the Air Force are all engaged in the support of theoretical mathematics and many of the foregoing suggestions would apply to their operations. In particular, one might note the program undertaken by OOR and OSR to strengthen regional research centers by bringing to them small research groups centered around a strong foreign mathematician.

It is important for the development of the National Science Foundation at this stage to present the proposals for research support so that the somewhat different needs of mathematics may be appraised both as to their nature and their extent. It is important to eliminate all unnecessary items, all unrealistic items, and all luxury items from the budgets of these proposals. Finally it is important to be relaxed about the outcome of the requests, for the Foundation will do what it can.

Tulane University and Fund for the Advancement of Education 